\title{
EFEITOS DO MILHO BT SOBRE A ENTOMOFAUNA
}

\author{
Efects of Bt Corn Under the Insects
}

\begin{abstract}
Alberto Luiz Marsaro Júnior ${ }^{1}$
\section{Resumo}

Bacillus thuringiensis (Bt) é, atualmente, o inseticida biológico mais produzido no mundo, usado como agente de controle de pragas. Essa bactéria produz cristais de proteínas inseticidas, que são tóxicos quando ingeridos pelos insetos. Recentemente, essas toxinas estão sendo expressas em plantas transgênicas, como o milho, objetivando o controle de pragas. Estudos têm demonstrado que essas plantas são, em alguns casos, até mais eficientes que outros agentes de controle, químico ou biológico. Existem estudos que mostram que o milho Bt é específico para as pragas alvo de controle. Porém, alguns estudos mostram que a ingestão do pólen desse milho pode afetar insetos que não são alvos de controle. As plantas transgênicas expressando as toxinas da bactéria Bacillus thuringiensis poderão auxiliar de maneira significativa no controle de pragas, contribuindo para a redução do uso de inseticidas químicos sintéticos e os danos causados pelos agrotóxicos ao meio ambiente. A decisão da adoção das plantas transgênicas no controle de pragas vai depender dos riscos e benefícios para o homem e o meio ambiente, que essa nova estratégia de controle tem com relação às outras estratégias.
\end{abstract}

Palavras-chave: Insecta; Plantas transgênicas; Resistência de plantas.

\section{Abstract}

Bacillus thuringiensis (Bt) is, now, the most produced biological insecticide in the world, used as agent of pests control. This bacterium produces crystals of insecticide proteins, which are toxic to some insects when ingested by them. Recently, these toxins are being expressed in transgenic plants, as the corn, aiming the control of pests. Studies have been demonstrating that these plants are, in some cases, even more efficient than other chemical or biological control agents. Some studies have been demonstrating that the Bt corn is appropriated for the control of specific target pests. However, studies shows that the ingestion of the pollen of these corns can affect non-target insects of the control. The transgenic plants expressing the toxins of Bt can aid in a significant way in the control of pests, contributing to the reduction of the use of synthetic chemical insecticides and the damages caused by the chemicals to the environment. The decision for use the transgenic plants for pests control will depend on the advantages for the man and the environment, as compared to other control alternatives.

Keywords: Insecta; Transgenic plants; Plant resistance.

1 Entomologista, Embrapa Roraima, Br174, km 8, Distrito Industrial, CP 133, CEP 69301-970, Boa Vista/RR, alberto@cpafrr.embrapa.br. 


\section{A bactéria Bacillus thuringiensis}

Bacillus thuringiensis (Bt) é, atualmente, o inseticida biológico mais produzido no mundo, usado como agente de controle de pragas. Em 1995, as vendas mundiais foram calculadas em 90 milhões de dólares, representando aproximadamente $2 \%$ do total global do mercado de inseticidas. Além disso, até princípios de 1998, haviam sido registrados aproximadamente 200 produtos à base de Bt nos Estados Unidos (SCHNEPF et al., 1998).

A bactéria $B$. thuringiensis, que é encontrada naturalmente no solo, tem sido usada para produzir inseticida biológico, para aplicação foliar, desde 1938 (KOZIEL et al. 1993a). Sua utilização como inseticida só é possível porque essa bactéria, além de produzir esporos, sintetiza estruturas glicoprotéicas sólidas, denominadas de d-endotoxinas ou cristais de proteínas inseticidas, que são tóxicos quando ingeridos pelos insetos.

Essas proteínas são codificadas por diferentes genes, sendo possível se encontrar até cinco tipos de proteínas numa mesma célula bacteriana, como em B. thuringien sis subesp. israelensis, todas com atividade inseticida contra larva de mosquitos (RABINOVITCH et al., 1998).

Os vários cristais de proteínas inseticidas têm sido classificados de acordo com seu espectro de atividade e na homologia das suas seqüências de aminoácidos. Assim, a classificação proposta por Hofte; Whiteley (1989) coloca os cristais de proteínas inseticidas conhecidos em quatro grandes classes. A primeira classe, representada pela endotoxina CryI, são as proteínas ativas contra Lepidoptera, CryII são as proteínas ativas contra Lepidoptera e Diptera, CryIII ativas contra Coleoptera e CryIV ativas contra Diptera.

Em 1992, Tailor e colaboradores identificaram um cristal de proteína inseticida com atividade contra Lepidoptera (Ostrinia nubilalis) e Coleoptera (Leptinotarsa decemlineata) e sugeriram que proteínas ativas contra essas duas ordens fosse colocada em uma nova classe, a das proteínas CryV.

A infecção da praga pela bactéria iniciase quando um inseto suscetível ingere cristais de Bt. Esses cristais são compreendidos por pró-toxinas que, após a ingestão, são solubilizadas pelo $\mathrm{pH}$ alcalino do trato intestinal do inseto. Após a solubilização, a maioria das pró-toxinas conhecidas atualmente precisam ser clivadas por proteases intestinais para tomarem-se fragmentos ativos.
Uma vez ativos, os fragmentos de pró-toxinas se ligam em receptores específicos encontrados no epitélio do inseto. Como conseqüência disso, ocorre a deformação das células epiteliais do intestino médio e a desintegração da membrana microvilar, o que acarreta na destruição do intestino. Uma vez que o funcionamento do intestino médio é interrompido, ocorre uma redução do $\mathrm{pH}$ do fluido intestinal, conjuntamente com uma liberação de nutrientes, os quais criam condições para a germinação de esporos de Bt e para a multiplicação de suas células vegetativas. O Bt então invade os tecidos larvais do inseto, que eventualmente interrompe sua alimentação e morre. Devido ao processo infeccioso, o inseto se torna mais suscetível a invasões microbianas secundárias que podem acelerar a sua morte. O ciclo infeccioso é concluído quando o cadáver é consumido e o Bt garante a sua perpetuação no ambiente na forma de esporo (LAMBERT; PEFEROEN, 1992).

O modo de ação das proteínas Cry difere completamente dos modos de ação dos conhecidos inseticidas químicos sintéticos, fazendo com que essas proteínas sejam elementos chaves para auxiliar no manejo integrado de pragas por meio de sua aplicação foliar sobre as plantas ou, como mais recentemente, pela expressão dessas toxinas em plantas transgênicas.

\section{Efeitos do milho Bt sobre os insetos-praga}

A primeira planta transgênica, expressando toxinas de $\mathrm{B}$. thuringiensis, desenvolvida com o objetivo de se controlar pragas, foi o tabaco, cujos alvos eram lagartas desfolhadoras (BARTON et al., 1987). Após o tabaco, um grande número de plantas, também expressando as toxinas de Bt, foi desenvolvido, objetivando o controle de pragas, destacando-se entre elas, o algodão, batata, arroz, milho e tomate (PERLAK et al., 1990; ADANG et al., 1993; FUJIMOTO et al., 1993; KOZIEL et al., 1993b; MANDAOKAR et al., 2000, respectivamente). Dentre essas culturas, o milho é a mais promissora e a de maior investigação científica.

Diversos estudos na literatura têm mostrado que a resistência do milho Bt para larvas de Spodoptera frugiperda (Lepidoptera: Noctuidae), uma das principais lagartas desfolhadoras do milho, tem sido superior às linhagens não transgênicas (WILUAMS et al., 1999; LYNCH et al., 1999). 
Em um outro estudo, Lorenz; Langenbruch (2000) demonstraram que o milho Bt é mais resistente para uma das mais importantes pragas do milho dos Estados Unidos, Ostrinia nubilalis (Lepidoptera: Pyralidae), quando comparado com os não transgênicos.

Além das pragas importantes, pragas secundárias do milho, Papaipema nebris, Helicoverpa zea e Mythima unipuncta , ambas (Lepidoptera: Noctuidae), também têm se mostrado suscetíveis, quando alimentadas com folhas de milho Bt, tanto em laboratório como em campo (PILCHER et al., 1997a).

O milho Bt também tem se mostrado mais resistente para pragas que atacam o colmo do milho, como Diatraea grandiosella (Lepidoptera: Crambidae), quando comparado com o milho não Bt, conforme demonstrado por Barry et al. (2000). Resultados semelhantes também foram demonstrados por Jansen et al. (1997), porém, os autores trabalharam com a praga O. nubilalis. Ambos os autores verificaram que o comprimento da galeria no colmo do milho Bt, provocada pelas larvas, era significativamente menor que o do milho não Bt.

As toxinas de Bt também podem se manifestar na palha da espiga do milho e afetar significativamente a biologia de pragas, caso esse material faça parte da dieta alimentar dos insetos, conforme foi observado para S. frugiperda, D. grandiosella e H. zea, por Williams et al. (1998). Resultados semelhantes também foram observados por Williams et al. (1997), porém, os autores avaliaram o efeito das toxinas somente para S. frugiperda e D. grandiosella.

A mais importante praga da espiga, $\mathrm{H}$. zea também pode ter seus danos significativamente reduzidos quando esse inseto se alimenta de espigas, que expressam toxinas de Bt no momento da abertura das galerias, conforme constatado por Sims et al. (1996). Resultados semelhantes foram encontrados por Archer et al. (2001). Ambos os autores verificaram, porém, que houve diferenças com relação à resistência conferida pelos híbridos Bt avaliados para $\mathrm{H}$. zea.

Archer et al. (2001), que trabalharam com os eventos de híbridos Bt (Mon810, Bt11, Bt176 e CBH354), justificaram que o evento Bt 176 não providenciou um controle eficiente de $\mathrm{H}$. zea, com relação aos demais eventos, porque nesse a toxina não se manifestou em tecidos reprodutivos. Essa informação é corroborada por Koziel et al. (1993b), que afirmaram que o evento Bt176 expressa toxina somente nas folhas, haste, raiz e pólen e que a quantidade da toxina declina após a planta entrar em antese (início do florescimento). Por outro lado, os demais eventos conferiram um bom nível de controle sobre $\mathrm{H}$. zea, porque a toxina foi expressa na espiga e em concentrações suficientes para reduzir o dano da praga. Essa argumentação é fundamentada, uma vez que Armstrong et al. (1995) mencionaram que os eventos BT11 e MON810 expressam a toxina em estruturas vegetativas e reprodutivas.

Archer et al. (2000) estudaram os danos provocados por infestações artificiais de O. nubilalis e D. grandiosella sobre híbridos de milho $\mathrm{Bt}$, dos quatro eventos citados acima, em dois estágios do desenvolvimento da cultura, um antes e outro após a antese (durante o estágio de formação da espiga). Os autores verificaram que os quatro eventos proporcionaram um bom nível de controle para a primeira geração de ambas as pragas, as quais foram infestadas no primeiro estágio da cultura. No entanto, para a segunda geração das pragas, que foram infestadas no segundo estágio da cultura, somente os três eventos (Mon810, Bt11 e CBH354) proporcionaram um bom nível de controle. O evento Bt176 não foi eficiente para reduzir os danos das pragas, quando comparado com os demais. $\mathrm{O}$ fato de este evento reduzir a quantidade de toxina após a antese e possibilitar o desenvolvimento de uma segunda geração larval, conforme observado nesse trabalho, aumenta os riscos para o surgimento de populações resistentes às toxinas, quando comparados com híbridos que mantêm altas concentrações de toxinas durante todo o ciclo da cultura.

Uma importante praga que ataca grãos armazenados, Plodia interpunctella (Lepidoptera: Pyralidae) também já se mostrou suscetível, quando alimentada com grão de milho expressando as toxinas Cry1Ab, conforme demonstrado por Giles et al. (2000). Os autores observaram que o desenvolvimento e a sobrevivência da praga foram reduzidos, quando comparados com os insetos criados com o milho não Bt. Além disso, os autores concluíram que os grãos de milho Bt contendo a referida toxina podem afetar significativamente as populações de P. interpunctella suscetíveis para B. thuringiensis, por quatro ou cinco meses após a colheita. 
$\mathrm{O}$ milho Bt tem-se revelado ainda, em alguns casos, mais eficiente no controle de pragas, quando comparado com inseticidas químicos sintéticos, fungos entomopatogênicos ou formulações de Bt. Labatte et al. (1996) avaliando a performance de três métodos de controle, inseticida chlorpyrifos, Beauveria bassiana e um híbrido de milho $\mathrm{Bt}$, sobre a larva de O. nubilalis, verificaram que não houve diferença significativa entre o primeiro e o segundo método, mas que o terceiro foi superior em relação aos demais. Clark et al. (2000), avaliando os danos provocados por larvas de $\mathrm{O}$. nubilalis em um cultivo de milho submetido a quatro tratamentos, milho Bt, inseticida permethrin, formulação de Bt e controle, verificaram que os danos aumentaram em ordem crescente, conforme a seqüência dos tratamentos listados.

Conforme demonstrado, as plantas transgênicas têm se revelado eficientes no controle de pragas e, nesse sentido, podem contribuir de maneira significativa para a redução do uso de inseticidas químicos sintéticos.

Finalmente, o milho Bt, por ser menos danificado por pragas, pode alcançar produções superiores às obtidas pelas linhagens não transgênicas. Essa afirmação pode ser validada por Singer et al. (2000), que mostraram que dentre os híbridos avaliados, os transgênicos produziram de 7 a $19 \%$ a mais que os correspondentes não transgênicos.

\section{Efeitos do milho Bt sobre os insetos não pragas}

As plantas transgênicas, além de poderem contribuir de maneira significativa para o Manejo Integrado de Pragas (MIP), têm sido consideradas como seguras para a entomofauna, visto que estudos têm demonstrado que essas plantas não têm apresentado efeito para insetos não alvos de controle. Dentre esses estudos, destaca-se o de Lozzia (1999), que avaliou os efeitos do milho Bt sobre diversos grupos de insetos associados à cultura e à praga O. nubilalis, tais como, Carabidae, Chrysomelidae, Coccinellidae, Staphylinidae, Syrphidae e parasitóides da ordem Hymenoptera. Baseado nos resultados encontrados, o autor concluiu que não houve diferença significativa na abundância da entomofauna avaliada entre o milho Bt e o seu correspondente não transgênico.
Pilcher et al. (1997b) avaliaram o efeito da ingestão de pólen de milho Bt que continha a toxina Cry1Ab sobre três predadores, Coleomegilla maculata (Coleoptera: Coccinellidae), Orius insidiosus (Hemiptera: Anthocoridae) e Chrysoperla carnea (Neuroptera: Chrysopidae), e não encontraram diferença significativa para nenhum dos três insetos, quando comparados com o controle. Além disso, os autores não detectaram diferenças no número de predadores (cocinelídeos, antocorídeos e crisopídeos) associados à O. nubilalis, quando comparados a campo, entre uma cultura de milho Bt e outra não Bt.

Lozzia et al. (1998) estudaram o desenvolvimento de Rhopalosiphum padi (Homoptera: Afididae) quando esse era alimentado com folhas de milho Bt e o efeito da ingestão desse afídio quando predado por C. carnea. Os autores verificaram que não houve efeito no desenvolvimento dos dois insetos estudados.

Entretanto, existem estudos demonstrando o contrário, ou seja, que as plantas transgênicas apresentam efeitos sobre organismos não alvo de controle. Num desses estudos, Jesse; Obrycki (2000) avaliaram o efeito da ingestão de folhas de Asclepias syriaca que continham deposição natural de pólen de milho Bt, por larvas de Danaus plexippus (Lepidoptera: Danaidae), e concluíram que a mortalidade dessas larvas foi significativamente maior que a das larvas alimentadas com folhas de pólen não Bt. Pieris brassicae (Lepidoptera: Pyralidae), Pieris rapae (Lepidoptera: Pieridae) e Plutella xylostella (Lepidoptera: Yponomeutidae) também mostraram significante mortalidade quando ingeriram folhas de repolho contaminadas por pólen de milho Bt (FELKE; LANGENBRUCH, 2001).

Widmer et al. (1997) utilizaram genes marcadores, que estão presentes em plantas transgênicas, com o objetivo de avaliar a persistência do DNA genômico das plantas transformadas, quando essas foram colocadas para se decompor no solo. Os autores verificaram que o DNA genômico pode persistir no solo ou em condições de campo por vários meses.

A persistência da atividade das proteínas inseticidas no solo tem sido atribuída às ligações e/ ou afinidades que essas proteínas têm para com as argilas e/ou ácidos húmicos presentes no solo (CRECCHIO; STOTZKY, 1998). Quando as toxinas de Bt entram em contato com o solo, uma parte 
fica livre e é facilmente utilizada como fonte de carbono e/ou nitrogênio pelos microorganismos do solo. A outra parte se liga a partículas de argila no solo, o que reduz a capacidade dos microorganismos de utilizar a toxina como fonte de nutrientes (KOSKELLA; STOTZKY, 1997).

Devido a essa complexa interação com as partículas do solo, as toxinas podem continuar ativas nesse ambiente por muitas semanas. Esse fato foi comprovado por Saxena; Stotzky (2000), que avaliaram o efeito de suspensões de solo, retiradas da região da rizosfera de plantas de milho Bt, sobre larvas de Manduca sexta (Lepidoptera: Sphingidae). Os autores obtiveram índices de mortalidade larval que chegaram a $100 \%$, após 40 dias de crescimento da cultura. Demonstraram, portanto, que as toxinas são liberadas pelas raízes das plantas e podem se manter ativas, devido às interações com as partículas do solo, por muitas semanas.

\section{Considerações finais}

As plantas transgênicas expressando as toxinas da bactéria Bacillus thuringiensis poderão auxiliar de maneira significativa no controle de pragas, contribuindo para a redução do uso de inseticidas químicos sintéticos, os custos de produção e os danos causados pelos agrotóxicos ao meio ambiente.

O milho Bt apresenta efeitos para os insetos não alvos de controle, porque suas toxinas são expressas em diferentes partes da planta e não somente nas regiões de ataque das pragas. A biotecnologia poderá, num futuro próximo, desenvolver plantas que expressem as toxinas somente nos locais de ataque dos insetos-praga, minimizando, assim, o efeito sobre os insetos não alvos de controle.

O uso de milho Bt no controle de pragas deverá crescer muito nos próximos anos, porque as proteínas que têm sido estudadas até o momento não são patogênicas para os mamíferos, pássaros, anfíbios ou répteis e são muito específicas para os grupos de insetos e invertebrados-praga, contra os quais as toxinas têm atividade.

A decisão da adoção das plantas transgênicas no controle de pragas vai depender dos riscos e benefícios, para o homem e o meio ambiente, que essa nova estratégia de controle tem com relação às outras estratégias.

\section{Referências}

ADANG, M. J., et al. The reconstruction and expresssion of a Bacillus thuringien siscryIIIA gene in protoplasts and potato plants. Plant Mol. Biol., v. 21, p. 1131-1145, 1993.

ARCHER, T. L, et al. Whorl and stalk damage by European and Southwestern corn bores to four events of Bacillus thuringiensis transgenic maize. Crop Protection, v. 19, p. 181-190, 2000.

ARCHER, T. L et al. Ear and shank damage by corn borers and corn earworms to four events of Bacillus thuringiensis transgenic maize. Crop Protection, v. 20, p. 139-144, 2001.

ARMSTRONG, C. L, et al. Field evaluation of European corn borer control in progeny of 173 transgenic corn events expressing an insecticidal protein from Bacillusthuringiensis. Crop Science, v. 35, p. 550-557, 1995.

BARRY, B. D., etal. Performance of transgenic corn hybrids in Myssouri for insect control and yield. Journal of Economic Entomology, v. 93, n. 3, p. 993-999, 2000.

BARTON, K. A.; WHITELEY, H. R.; YANG, N. S. Bacillus thuringiensis d-endotoxin expressed in transgenic Nicotiana tabacum provides resistance to lepidopteran insects. Plant Physiol., v. 85, p. 1103-1109, 1987.

CLARK, T. L, et al. Comparison of Bt (Bacillus thuringiensis Berliner) maize and conventional measures for control of the European corn borer (Lepidoptera: Cambridae). Journal of Entomologycal Science, v. 35, n. 2, p. 118-128, 2000.

CRECCHIO, C.; STOTZKY, G. Insecticidal activity and biodegradation of the toxin from Bacillus thuringiensissubsp. kurstaki bound to humic acids from soil. Soil Biology and Biochemistry, v. 30, n. 4, p. 463-470, 1998.

FELKE, M.; LANGENBRUCH, G. A. Does Bt-pollen harm butterflies?Gesunde Pflanzen, v. 53, n. 1, p. 24-28, 2001.

FUJIMOTO, H., et al. Insect resistant rice generated by introduction of a modified d-endotoxin gene of Bacillus thuringiensis. Bio/Technology, v. 11, p. 1151-1155, 1993. 
GILES, K. L et al. Effects of transgenic Bacillus thuringiensis maize grain on $\mathrm{B}$. thuringiensissusceptible Plodia interpunctella (Lepidoptera: Pyralidae). Journal of Economic Entomology, v. 93, n. 3, p. 1011-1016. 2000.

HOFTE, H.; WHITELEY, H. R. Insecticidal crystal proteins of Bacillusthuringiensis. Microbiological Reviews, v. 53, p. 242-255, 1989.

JANSEN, S., et al. Transgenic com expressing a Cry9c insecticidal protein from Bacillusthuringiensis protected from European corn borer damage. Crop Science, v. 37, n. 5, p. 1616-1624, 1997.

JESSE, L C. H.; OBRYCKI, J. J. Field deposition of Bt transgenic corn pollen: lethal effects on the monarch butterfly. Oecologia, v. 125, n. 2, p. 241248, 2000.

KOSKELA, J.; STOTZKY, G. Microbial utilization of free and clay-bound insecticidal toxins from Bacillus thuringiensis and their retention of insecticidal activity after incubation with microbes. Appl. Environ. Microbiol., v. 63, p. 3561-3568, 1997.

KOZIEL, M. G., etal. The insecticidal crystal proteins of Bacillus thuringiensis: past, present e future uses. Biotechnology and Genetic Engineering Reviews, v. 11, p. 171-228, 1993 .

KOZIEL, M. G., et al. Field performance of elite transgenic maize plants expressing an insecticidal protein derived from Bacillus thuringiensis. Bio/ Technology, v. 11, p. 194-200, 1993b.

LABATTE, J. M., et al. Field evaluation of and modeling the impact of three control methods on the larval dynamics of Ostrinia nubilalis (Lepidoptera: Pyralidae). Journal of Economic Entomology, v. 89, n. 4, p. 852-862, 1996.

LAMBERT, B.; PEFEROEN, M. Insecticidal promise of Bacillusthuringiensis. Bioscience, v. 42, n. 2, p. 112-122, 1992.

LORENZ, N.; LANGENBRUCH, G. A. No chance for the corn borer: feeding behaviour and mortality rate of corn borer larvae on Bt-maize. Mais, n. 3, p. 130-131, 2000.

LOZZIA, G. C., et al. Effects of Bt corn on Rhopalosiphum padi L. (Rhynchota Aphididae) and its predatorChrysoperla carnea Stephen (Neuroptera
Chrysopidae). Bollettino di Zoologia Agraria e di Bachicoltura, v. 30, n. 2, p. 153-164, 1998.

LOZZIA, G. C. Biodiversity and structure of ground beetle assemblages (Coleoptera: Carabidae) in Bt corn and its effects on non target insects. Bollettino di Zoologia Agraria e di Bachicoltura, v. 31, n. 1, p. 37-50, 1999.

LYNCH, R.E., et al. Evaluation of transgenic sweet corn hybrids expressing CryIA (b) toxin for resistance to corn earworm and fall armyworm (Lepidoptera: Noctuidae). Journal of Economic Entomology, v. 92, n. 1, p. 246-252, 1999.

MANDAOKAR, A. D., et al. Transgenic tomato plants resistant to fruit borer (Helicoverpa armigera Hubner). Crop Protection, v. 19, p. 307-312, 2000.

PERLAK, F. J., et al. Insect resistant cotton plants. Bio/Technology, v. 8, p. 939-943, 1990.

PILCHER, C. D., etal. Field and laboratory evaluations of transgenic Bacillus thuringiensis corn on secondary pests (Lepidoptera: Noctuidae). Journal of Economic Entomology, v. 90, n. 2, p. 669-678, 1997a.

PILCHER, C. D., et al. Preimaginal development, survival, and field abundance of insectpredators on transgenic Bacillus thuringiensis corn. Environmental Entomology, v. 26, n. 2, p. 446454, 1997b.

RABINOVITCH, L; CAVADOS, C. F. G.; LIMA, M. M. Bacillus entomopatogênicos. Biotecnologia Ciência \& Desenvolvimento, n. 6, p. 40-41, 1998.

SAXENA, D.; STOTZKY, G. Insecticidal toxin from Bacillus thuringiensis is released from roots of transgenic Bt corn in vitro and in situ. FEMS Microbiology Ecology, v. 33, p. 35-39, 2000.

SCHNEPF, E., et al. Bacillus thuringiensis and its pesticidal crystal proteins. Microbiology and Molecular Biology Reviews, v. 62, n. 3, p. 775806, 1998.

SIMS, S. R.; PERSHING, J. C.; REICH, B. J. Field evaluation of transgenic corn containing a Bacillus thuringiensis Berliner insecticidal protein gene against Helicoverpa zea (Lepidoptera: Noctuidae). Journal of Entomological of Science, v. 31, n. 3, p. 340-346, 1996. 
SINGER, J. W.; HECKMAN, J. R; INGERSO NMAHAR, J.; WESTENDORF, M. L. Hybrid and nitrogen source affect yield and European corn borer damage. Journal of Sustainable Agriculture, v. 16, n. 1, p. 5-15, 2000.

TAILOR, R, etal. Identification and characterization of a novel Bacillus thuringiensis d-endotoxin entomocidal to coleopteran and lepidopteran larvae. Molecular Microbiology, v. 6, p. 1211-1217, 1992.

WIDMER, F., et al. Quantification of transgenic plantmarkergene persistence in the field. Molecular Ecology, v. 6, n. 1, p. 1-7, 1997.
WILLIAMS, W. P., et al. Transgenic corn evaluated for resistance to fall armyworm and southwestern corn borer. Crop Science, v. 37, n. 3, p. 957-962, 1997.

WILUAMS, W. P., et al. Evaluation of transgenic corn for resistance to corn earworm (Lepidoptera: Noctuidae), fall armyworm (Lepidoptera: Noctuidae), and southwestern corn borer (Lepidoptera: Crambidae) in a laboratory bioassay. Journal of Agricultural Entomology, v. 15, n. 2, p. 105-112, 1998.

WILLAMS, W. P., et al. Enhancing inherent fall armyworm (Lepidoptera: Noctuidae) resistance of corn with Bacillus thuringiensis genes. Florida Entomologist, v. 82, n. 2, p. 271-277, 1999. 